\title{
Resíduo de laticínio em pastagem de capim Mombaça: atributos químicos da forragem e do solo ${ }^{1}$
}

\section{Waste the processing of milk products in pasture of Mombaça grass: attributes chemicals of grass and soil}

\author{
Perlon Maia dos Santos ${ }^{2}$; Antonio Clementino dos Santos ${ }^{3 *}$; \\ José Expedito Cavalcante da Silva ${ }^{3}$
}

\section{Resumo}

A aplicação de resíduo líquido de laticínio (RLL) no solo sob pastagens pode fornecer nutrientes a cultura e diminuir a poluição gerada por laticínios via ciclagem de nutrientes entre o campo e o meio urbano. Com o objetivo de avaliar o uso de doses resíduo líquido de laticínio $(10,50,100,150,200$ e $\left.400 \mathrm{~m}^{3} \mathrm{ha}^{-1}\right)$ de RLL, na composição química em nitrogênio $(\mathrm{N})$, fósforo $(\mathrm{P})$ e potássio $(\mathrm{K})$ do capim Mombaça, bem como a extração destes elementos do solo, além de avaliar a fertilidade química em $\mathrm{P}, \mathrm{K}^{+}, \mathrm{Ca}^{2+}, \mathrm{Na}^{+}, \mathrm{Mg}^{2+}, \mathrm{Al}^{3+}, \mathrm{H}^{+}$e matéria orgânica (MO) do Neossolo Quartzarênico, foi realizado um estudo em quatro ciclos de produção, onde se observou que o RLL contribuiu para o aumento da proteína bruta, do $\mathrm{P}$ e do $\mathrm{K}^{+}$vegetal. No solo foi observado aumento dos teores de $\mathrm{P}, \mathrm{K}^{+}, \mathrm{Ca}^{2+}, \mathrm{Na}^{+}$e $\mathrm{MO}$, alterando positivamente sua fertilidade. O RLL pode substituir parcialmente a adubação fosfatada e, completamente, a adubação potássica.

Palavras-chave: Adubação orgânica, químicas do solo, ciclagem de nutrientes

\begin{abstract}
The application of waste liquid from the processing of milk products (RLL) in pastures might provide nutrients to the crops and also contribute to reduce of the pollution generated by industrialization processes of milk, by recycling of nutrients between the countryside and urban environment. With the objective to evaluate the use of RLL rates of 10, 50, 100, 150, 200 and $400 \mathrm{~m}^{3} \mathrm{ha}^{-1}$ considering nitrogen $(\mathrm{N})$, phosphorus $(\mathrm{P})$ and potassium $(\mathrm{K})$ chemical characteristics of Guinea grass cultivar Mombasa and the entisol fertility a study in four cycles of production was carried out. It was observed that the RLL led to increased the rude protein, $\mathrm{P}$ and the tissue $\mathrm{K}^{+}$contents. The soil levels of $\mathrm{P}, \mathrm{K}^{+}, \mathrm{Ca}^{2+}, \mathrm{Na}^{+}$ and $\mathrm{MO}$ were increased, changing positively its chemical fertility. The RLL can substitute partially the phosphorus fertilization, as well as the whole potassium fertilization.
\end{abstract}

Key words: Organic fertilization, chemical composition of grass, to recycle of nutrients

${ }^{1}$ Dissertação de Mestrado do primeiro autor.

${ }^{2}$ Discente de Doutorado do Programa de Pós-Graduação em Ciência Animal Tropical, Centro de Ciência Animal, Universidade Federal do Tocantins, UFT, BR 153, Km 112, Araguaína, TO, CEP 77804-970. E-mail: perllon_zoo@yahoo.com.br

${ }^{3}$ Profs. do Programa de Pós-Graduação em Ciência Animal Tropical, Centro de Ciência Animal, UFT, Araguaína, TO. E-mail: clementino@uft.edu.br; jecs@uft.edu.br

* Autor para correspondência 


\section{Introdução}

A intensificação do uso de pastagens tropicais é cada vez mais freqüente, entretanto a negligência da adubação, devido o alto custo dos insumos, tem prejudicado a sustentabilidade do sistema soloplanta e a produção animal. Se em uma área ocorre baixa disponibilidade de nutriente, como os baixos teores de $\mathrm{K}^{+}$observados em $85 \%$ dos solos do Cerrado (ERNANI; ALMEIDA; SANTOS, 2008), em outra, há excesso de elementos, como $\mathrm{N}, \mathrm{P}, \mathrm{I}$ e $\mathrm{K}$, dentre outros, derivados da deposição contínua de resíduos de produtos de consumo, que promovem a contaminação do solo e da água (McDOWELL; KOOPMANS, 2006). Sob uma perspectiva otimista é possível entrever uma solução ambientalmente correta para estes dois entraves ao se considerar a adubação alternativa com uso de resíduos.

Nos solos tropicais, que apresentam um complexo sortivo formado por argilas de baixa atividade (argilas 1:1 e óxidos), pobres em matéria orgânica e com baixa soma de bases e capacidade de troca catiônica (RICCI; PADOVANI; PAULA JUNIOR, 2010), como o Neossolo Quartzarênico, que ainda pode se apresentar ácido (MESQUITA et al., 2004), a aplicação de resíduos da agroindústria pode alterar positivamente sua fertilidade pelo fornecimento de C orgânico, P, Ca e K (MEDEIROS et al., 2007). A aplicação do resíduo líquido de laticínio (RLL) aumenta os teores de $\mathrm{Ca}, \mathrm{P}$ e $\mathrm{K}$ do solo e eleva as quantidades de nutrientes absorvidos pelas plantas melhorando seu valor nutricional (GHERI; FERREIRA, DA CRUZ, 2003). Entretanto, o melhor entendimento das modificações nos atributos químicos do solo, decorrente do uso deste resíduo, pode fornecer subsídios para a produção em bases sustentáveis sem comprometer o ambiente, além de assegurar a produtividade das pastagens e a reciclagem de nutrientes entre o campo e o meio urbano. O objetivo com o estudo foi analisar o efeito da aplicação direta, sem tratamento prévio, do resíduo líquido de laticínio nas características químicas do capim Mombaça e do Neossolo Quartzarênico, e quantificar a extração de nutrientes pelas plantas.

\section{Material e Métodos}

O estudo foi realizado na Escola de Medicina Veterinária e Zootecnia, da Universidade Federal do Tocantins, na cidade de Araguaína - TO, nas seguintes coordenadas geográficas: $7^{\circ} 06^{\prime} 17.16$ $\mathrm{S}$ e $48^{\circ} 12^{\prime} 02.83 \mathrm{O}$. A região é classificada como ecótono Cerrado e Floresta Amazônica, com clima tipo Aw (quente e úmido - Köppen), com chuvas de outubro a abril, alcançando precipitação média anual de $1.863 \mathrm{~mm}$. A altitude é de $240 \mathrm{~m}$ e a umidade relativa do ar é de $78 \%$. Os dados climáticos referentes ao período experimental foram coletados na estação meteorológica do Instituto Nacional de Meteorologia, localizada na EMVZUFT. A distribuição da temperatura e a precipitação pluviométrica podem ser vistas na Tabela 1. O solo da área experimental foi classificado como Neossolo Quartzarênico Órtico (EMBRAPA, 2006). Antes do estabelecimento do pasto foi realizada a caracterização da fertilidade do solo nas camadas 0-20 e 20-40 cm (Tabela 2). 
Tabela 1. Valores de temperatura, umidade e precipitação pluviométrica do ano de 2010 e média dos últimos 10 anos.

\begin{tabular}{|c|c|c|c|c|c|c|}
\hline \multirow{2}{*}{ Mês } & \multicolumn{3}{|c|}{ Temperatura média do ar $\left({ }^{\circ} \mathrm{C}\right)$} & \multirow{2}{*}{$\begin{array}{c}\text { Umidade } \\
(\%)\end{array}$} & \multirow{2}{*}{$\begin{array}{l}\text { Precipitação } \\
(\mathrm{mm})\end{array}$} & \multirow{2}{*}{ Ciclos } \\
\hline & Máxima & Mínima & Média & & & \\
\hline JAN & 30,50 & 21,60 & 25,04 & 85 & 216,7 & \\
\hline FEV & 30,70 & 21,30 & 25,90 & 86 & 231,80 & $1^{\circ}$ \\
\hline MAR & 30,40 & 21,50 & 26,30 & 86 & 250,80 & $2^{\circ}$ \\
\hline ABR & 30,60 & 21,40 & 26,30 & 82 & 272,80 & $3^{\circ}$ \\
\hline MAI & 31,40 & 20,60 & 26,90 & 77 & 16,00 & $4^{\circ}$ \\
\hline Total & & & 25,2 & & 1122,80 & \\
\hline \multicolumn{7}{|c|}{ Média nos últimos 10 anos } \\
\hline JAN & 31,25 & 21,59 & 25,11 & 86 & 248,1 & \\
\hline FEV & 30,80 & 21,69 & 25,06 & 87 & 265,3 & \\
\hline MAR & 30,60 & 21,55 & 25,05 & 87 & 295,6 & \\
\hline ABR & 30,65 & 21,50 & 25,30 & 86 & 226 & \\
\hline MAI & 31,65 & 21,40 & 25,10 & 82 & 97,9 & \\
\hline Total & & & 25,1 & & 1132,9 & \\
\hline
\end{tabular}

Fonte: Instituto Nacional de Meteorologia (INMET, 2010). Média histórica dos últimos 10 anos.

Tabela 2. Características químicas e físicas médias de Neosolo Quartzarênico Órtico da Fazenda da Universidade Federal do Tocantins, Araguaína, por ocasião da instalação do experimento, em novembro de 2009.

\begin{tabular}{|c|c|c|c|c|c|c|c|c|c|c|}
\hline Camada & M.O. ${ }^{(1)}$ & $\mathrm{pH}$ & $\mathrm{P}$ & $\mathrm{K}^{+}$ & $\mathrm{Ca}^{2+}$ & $\mathrm{Mg}^{2+}$ & $\mathrm{H}^{+}+\mathrm{Al3}^{+}$ & $\mathrm{SB}^{(2)}$ & $\mathrm{CTC}^{(3)}$ & $\mathrm{CTC}^{(4)}$ \\
\hline $\mathrm{cm}$ & $\mathrm{g} \mathrm{dm}^{-3}$ & $\mathrm{CaCl}_{2}$ & \multicolumn{2}{|c|}{$---\mathrm{mg} \mathrm{dm}^{-3}---$} & \multicolumn{3}{|c|}{----- $\mathrm{cmol}_{\mathrm{c}} \mathrm{dm}^{-3}$----- } & \multicolumn{3}{|c|}{$-----\mathrm{cmol}_{\mathrm{c}} \mathrm{dm}^{-3}-----$} \\
\hline $0-20$ & 15,8 & 4,06 & 0,60 & 11 & 1,53 & 1,48 & 3,96 & 3,15 & 7,2 & 3,4 \\
\hline \multirow[t]{3}{*}{$20-40$} & 15,2 & 4,17 & 0,55 & 12 & 0,52 & 0,75 & 4,8 & 1,23 & 6,15 & 5,6 \\
\hline & $\mathrm{V}^{(5)}$ & $\mathrm{m}^{(6)}$ & \multicolumn{2}{|c|}{ Dens. Ap..$^{(8)}$} & Areia & Silte & $\mathrm{CE}^{(7)}$ & Argila & \multicolumn{2}{|c|}{ Clas. Text. ${ }^{(9)}$} \\
\hline & \multicolumn{2}{|c|}{-------------\%o----------- } & \multicolumn{2}{|c|}{$\mathrm{g} \mathrm{cm}^{-3}$} & $\%$ & $\%$ & $\mathrm{ds} \mathrm{m}^{-1}$ & $\%$ & \multirow{2}{*}{\multicolumn{2}{|c|}{ Areia }} \\
\hline $0-20$ & 35,32 & 31,40 & \multicolumn{2}{|c|}{1,55} & 94,85 & 1,90 & 0,07 & 3,25 & & \\
\hline $20-40$ & 41,37 & 32,36 & & & 93,75 & 2,75 & 0,06 & 3,50 & \multicolumn{2}{|c|}{ Areia } \\
\hline
\end{tabular}

(1) M.O.: matéria orgânica, (2) SB: soma de bases, ${ }^{(3)}$ CTC: capacidade de troca de cátions, (4) CTC : capacidade efetiva de troca de cátions, ${ }^{(5)} \mathrm{V}$ : saturação por bases, ${ }^{(6)} \mathrm{m}$ : saturação por alumínio, ${ }^{(7)} \mathrm{CE}$ : condutividade elétrica, ${ }^{(8)}$ Dens. Ap.: densidade aparente, ${ }^{(9)}$ Clas. Text.: classe textural.

Fonte: Elaboração dos autores.

Para o plantio foi realizado o preparo convencional do solo método de cultivo mínimo em função das características do solo. Independente do tratamento foi realizada a correção do solo com base nos dados da análise de solo, pelo método de saturação de base $(\mathrm{V}=60 \%)$. Foi aplicado uma tonelada ha $^{-1}$ de calcário dolomítico no préplantio (PRNT 98\%). Foi semeada, a lanço, a cultivar Mombaça de Panicum maximum Jacq. em dezembro de 2009, a taxa de 4,5 kg de sementes puras viáveis por hectare. Quarenta dias após a emergência foi realizado um corte de uniformização, e posteriormente a pastagem formada ocorreu à aplicação do efluente.

O delineamento experimental utilizado foi o de blocos completos ao acaso, com oito tratamentos e quatro repetições, totalizando 32 unidades experimentais de $9 \mathrm{~m}^{2}$, sendo que a área útil de avaliação das plantas foi de $1 \mathrm{~m}^{2}$ por repetição de cada tratamento. Foram estudadas seis doses de resíduo líquido de laticínio (RLL), correspondente aos volumes de: $10 ; 50 ; 100 ; 150 ; 200$ e $400 \mathrm{~m}^{3}$ ha1 , aplicadas nos dois primeiros ciclos de produção (janeiro e fevereiro) mais dois tratamentos 
adicionais, conforme metodologia de Oliveira et al. (2008), sendo que no terceiro e quarto ciclos foi verificado o efeito residual destas aplicações e dos tratamentos. O primeiro tratamento adicional foi o de dose zero, ou testemunha, que recebeu apenas calagem e o segundo tratamento adicional foi caracterizado pelo processo convencional de fertilização de pastagens, com o fornecimento de NPK nas doses recomendadas por Collier et al. (2008) sendo o N e K divididos em duas aplicações.
As doses do RLL foram aplicadas de forma uniforme com regador nas unidades experimentais. Nos tratamentos que não receberam o RLL (dose 0 e NPK), foi aplicada água, em quantidade intermediária ao volume das doses do resíduo (150 $\mathrm{m}^{3} \mathrm{ha}^{-1}$ ), para minimizar os efeitos de confundimento da água do resíduo. As características químicas do RLL, coletado imediatamente após sua produção, oriundo do Laticínio Biana Ltda de Araguaína, estão apresentadas na Tabela 3.

Tabela 3. Características do resíduo líquido de laticínio utilizado no experimento.

\begin{tabular}{lccc}
\hline Parâmetros & $1^{\circ}$ amostra & $2^{\circ}$ amostra & Técnica \\
\hline DBO $\left(\mathrm{mg} \mathrm{O}_{2} \mathrm{~L}^{-1}\right)$ & 25343,54 & 35765,19 & Titulometria \\
Nitrogênio $\left(\mathrm{mg} \mathrm{L}^{-1}\right)$ & & & \\
$\quad$ Amoniacal & 67,8 & 81,7 & Espectrofotometria \\
$\quad$ Nitrato & 7 & 8 & Espectrofotometria \\
$\quad$ Nitrito & 0,048 & 0,039 & Espectrofotometria \\
Ortofosfato $\left(\mathrm{mg} \mathrm{L}^{-1}\right)$ & 178,8 & 183 & Espectrofotometria \\
Sódio (mg L-1) & 112,94 & 107,88 & Fotometria de chama \\
Potásssio $\left(\mathrm{mg} \mathrm{L}^{-1}\right)$ & 735,29 & 715,97 & Fotometria de chama \\
Sólidos Totais $\left(\mathrm{mg} \mathrm{L}^{-1}\right)$ & 16244,4 & 14406 & Gravimetria \\
\hline
\end{tabular}

DBO: demanda bioquímica de oxigênio.

Fonte: Elaboração dos autores.

O total dos elementos químicos $\mathrm{N}, \mathrm{P}, \mathrm{K}^{+}$e $\mathrm{Na}^{+}$, fornecidos em cada aplicação estão apresentados na Tabela 4. A primeira aplicação foi realizada após corte de uniformização da pastagem já formada, no $5^{\circ}$ dia da rebrota. A segunda aplicação ocorreu após o corte de simulação do $1^{\circ}$ ciclo. O manejo de corte seguiu o modelo de sistema rotacionado com período de descanso de 28 dias e altura de corte de $30 \mathrm{~cm}$. As aplicações foram efetuadas de modo a evitar o contato do resíduo com o limbo foliar das plantas em função das características do resíduo, e sua possível promoção de efeitos de confundimento.

Tabela 4. Total de nutrientes fornecido nas duas aplicações do resíduo de acordo as doses utilizadas.

\begin{tabular}{|c|c|c|c|c|c|c|c|c|}
\hline \multirow{3}{*}{$\begin{array}{l}\text { Tratamentos } \\
\left(\mathrm{m}^{3} \mathrm{ha}^{-1}\right)\end{array}$} & \multicolumn{4}{|c|}{$1^{\circ}$ ciclo } & \multicolumn{4}{|c|}{$2^{\circ}$ ciclo } \\
\hline & \multicolumn{8}{|c|}{$\left(\mathrm{kg} \mathrm{ha}^{-1}\right)$} \\
\hline & $\mathrm{N}$ & $\mathrm{P}$ & $\mathrm{K}^{+}$ & $\mathrm{Na}^{2+}$ & $\mathrm{N}$ & $\mathrm{P}$ & $\mathrm{K}^{+}$ & $\mathrm{Na}^{2+}$ \\
\hline 10 & 0,7 & 1,8 & 7,34 & 1,13 & 0,8 & 1,83 & 7,14 & 1,07 \\
\hline 50 & 3,5 & 8,94 & 36,7 & 5,65 & 4,05 & 9,15 & 35,7 & 5,35 \\
\hline 100 & 7 & 17,8 & 73,56 & 11,3 & 8,1 & 18,3 & 71,5 & 10,7 \\
\hline 150 & 10,5 & 26,7 & 110,2 & 16,95 & 12,15 & 27,45 & 107,2 & 16,1 \\
\hline 200 & 14 & 35,6 & 146,9 & 22,6 & 16,2 & 36,6 & 142,9 & 21,4 \\
\hline 400 & 28 & 71,2 & 293,8 & 45,2 & 32,4 & 73,2 & 285,8 & 42,8 \\
\hline NPK & 50 & 80 & 60 & - & 50 & 0,0 & 20 & - \\
\hline
\end{tabular}

Fonte: Elaboração dos autores. 
Para as análises químicas, amostras de massa total de forragem seca foram preparadas para determinação dos teores de proteína bruta (PB), $\mathrm{P}$ e K. Para a determinação da porcentagem de PB total foi utilizado o método analítico semimicro Kjeldhal, após digestão sulfúrica. A partir da digestão sulfúrica também foi determinado o teor de P, por espectrofotometria de absorbância (BOARETTO et al., 2009). Pela digestão via úmida, (nítroco-perclórica) foram determinados os teores de $\mathrm{K}$, quantificados por fotometria de chama (BOARETTO et al., 2009). As extrações dos elementos N, P e K foram calculadas a cada ciclo em função da produção de biomassa e da concentração do elemento na massa seca total.

As análises do solo foram realizadas nas profundidades de 0-20 e 20-40 cm após quatro ciclos de produção. Foram realizadas as seguintes avaliações químicas: $\mathrm{P}$ melich (mg dm- $\left.{ }^{3}\right), \mathrm{C}$ orgânico $\left(\mathrm{mg} \mathrm{dm}-^{3}\right)$, acidez $\left(\mathrm{pH}\right.$ em $\left.\mathrm{CaCl}_{2}\right), \mathrm{K}^{+}$, $\mathrm{Ca}^{2+}, \mathrm{Mg}^{2+}$ acidez potencial $\left(\mathrm{H}^{+}+\mathrm{Al}^{3+}\right)$, soma de bases (SB), capacidade de troca catiônica (CTC), saturação por alumínio (m\%) e saturação por bases (V\%). As análises foram conduzidas no laboratório de solo do curso de Zootecnia da UFT segundo o método de Boaretto et al. (2009).

As respostas referentes às doses do RLL dentro de cada ciclo e entre ciclos foram submetidas a análise de variância. As médias foram avaliadas por modelos de regressão $\left(Y=\beta_{0}+\beta^{\mathrm{x} \mathrm{m}^{3} \mathrm{RLL}}+\right.$ Erro $)$ polinomial de primeiro e segundo grau para verificar a significância do efeito das doses de RLL nos atributos químicos da forragem, do solo e a extração de elementos dentro dos ciclos. A escolha da equação de regressão foi realizada com base no coeficiente de determinação, na significância da regressão e de seus coeficientes, avaliados ao nível de $5 \%$ de probabilidade, além da significância biológica da resposta. As respostas de características químicas da forragem e extração de elementos de cada dose ao longo dos quatro ciclos foram comparadas ( $\mathrm{Y}_{\mathrm{RLL}}$ $=\mu+$ Ciclo $_{\mathrm{x}(1-4)}+$ Bloco $_{\mathrm{z}(1-4)}+$ Erro) pelo teste Tukey a $5 \%$ de probabilidade. Foi analisado o contraste entre os tratamentos NPK e $200 \mathrm{~m}^{3}$, e NPK e 400 $\mathrm{m}^{3}$ de RLL, utilizando-se o teste Dunnet a $5 \%$ de probabilidade. Esta comparação foi realizada devido o fornecimento de $\mathrm{K}$ e $\mathrm{P}$ destas doses, nos dois ciclos onde houve a aplicação do RLL, terem extrapolado os valores destes elementos segundo a recomendação representada pelo tratamento NPK (Tabela 4).

\section{Resultados e Discussão}

As concentrações de N, P e K na parte área do capim Mombaça foram influenciadas pela aplicação do resíduo líquido de laticínio (RLL). Os teores de proteína bruta $(\mathrm{PB})$ ajustaram-se ao modelo linear de regressão à medida que se elevou as doses do resíduo até o $3^{\circ}$ ciclo (Tabela 5). A mineralização de compostos orgânico do RLL, como proteínas, o fornecimento direto de $\mathrm{NH}_{4}^{+}$e $\mathrm{NO}_{3}^{-}$e o aumento da $\mathrm{MO}$ promoveu o aumento do $\mathrm{N}$ no compartimento solo (CANTARELLA, 2007) o qual pôde ser assimilado pela planta. Efeitos da aplicação de resíduos agroindustriais sobre o teor de $\mathrm{PB}$ de gramíneas tropicais é relatado na literatura. Silva Neto et al. (2010) obtiveram aumento da PB no capim Marandú com a aplicação de resíduo líquido de frigorífico. Gheri, Ferreira e Da Cruz (2003) também reportaram incremento da concentração de $\mathrm{N}$ da parte aérea do capim Tanzânia devido aplicação de soro de leite. 
Tabela 5. Porcentagem de proteína bruta, teores de fósforo e potássio na parte aérea do capim Mombaça em função de cada nível de aplicação do resíduo líquido de laticínio ao longo de quatro ciclos produtivos e equação de regressão em função dos diferentes níveis dentro de cada ciclo.

\begin{tabular}{|c|c|c|c|c|c|}
\hline \multicolumn{6}{|c|}{ PB (\%) } \\
\hline Ciclos & $1^{\circ}$ & $2^{\circ}$ & $3^{\circ}$ & $4^{\circ}$ & \\
\hline Tratamentos & & & & & $\mathrm{CV}$ \\
\hline 0 & $9,4 \mathrm{a}$ & $8,9 \mathrm{a}$ & $8,3 \mathrm{a}$ & $6,4 \mathrm{~b}$ & 8,7 \\
\hline 10 & $9,8 \mathrm{a}$ & $10,1 \mathrm{a}$ & $5,3 \mathrm{c}$ & $6,8 \mathrm{~b}$ & 6,1 \\
\hline 50 & $9,8 \mathrm{a}$ & $9,4 \mathrm{a}$ & $5,3 \mathrm{c}$ & $7,5 \mathrm{~b}$ & 6,5 \\
\hline 100 & $10 \mathrm{a}$ & $10,1 \mathrm{a}$ & $5,8 \mathrm{c}$ & $7,5 \mathrm{~b}$ & 4,6 \\
\hline 150 & $9,9 \mathrm{a}$ & $10,4 \mathrm{a}$ & $6,2 \mathrm{~b}$ & $7,2 \mathrm{~b}$ & 5,4 \\
\hline 200 & $10,3 \mathrm{aA}$ & $10,6 \mathrm{aA}$ & $8,1 \mathrm{bB}$ & $7,9 \mathrm{bB}$ & 5,3 \\
\hline 400 & $10,7 \mathrm{aA}$ & $11,7 \mathrm{aA}$ & $8,2 \mathrm{bB}$ & $7,6 \mathrm{bB}$ & 5,9 \\
\hline NPK & $10,4 \mathrm{abA}$ & $12,3 \mathrm{aA}$ & $9,4 \mathrm{bA}$ & $9,8 \mathrm{bA}$ & 8,5 \\
\hline Equação & $\hat{Y}=9,67+0,0022 x$ & $\hat{\mathrm{Y}}=9,45+0,004 \mathrm{x}$ & $\hat{\mathrm{Y}}=6,07+0,005$ & $\hat{\mathrm{Y}}=6,99$ & \\
\hline \multicolumn{6}{|c|}{$\mathrm{P}\left(\mathrm{g} \mathrm{kg}^{-1}\right)$} \\
\hline 0 & $0,83 \mathrm{a}$ & $0,67 \mathrm{~b}$ & $0,62 \mathrm{~b}$ & $0,60 \mathrm{~b}$ & 7,2 \\
\hline 10 & $0,91 \mathrm{a}$ & $0,84 \mathrm{a}$ & $0,63 \mathrm{~b}$ & $0,60 \mathrm{~b}$ & 5,5 \\
\hline 50 & $0,96 \mathrm{a}$ & $0,98 \mathrm{a}$ & $0,66 \mathrm{~b}$ & $0,64 \mathrm{~b}$ & 6,3 \\
\hline 100 & $1,10 \mathrm{a}$ & $1,02 \mathrm{a}$ & $0,52 \mathrm{~b}$ & $0,57 \mathrm{~b}$ & 9,2 \\
\hline 150 & $1,01 \mathrm{a}$ & $1,03 \mathrm{a}$ & $0,64 \mathrm{~b}$ & $0,62 \mathrm{~b}$ & 11,3 \\
\hline 200 & $1,05 \mathrm{aA}$ & $0,96 \mathrm{aA}$ & $0,66 \mathrm{bB}$ & $0,60 \mathrm{bB}$ & 6,9 \\
\hline 400 & $0,89 \mathrm{aA}$ & $0,80 \mathrm{abA}$ & $0,74 \mathrm{abB}$ & $0,68 \mathrm{bB}$ & 14,4 \\
\hline NPK & $1,06 \mathrm{abA}$ & $1,12 \mathrm{aA}$ & $0,83 \mathrm{bA}$ & $0,70 \mathrm{bA}$ & 11,3 \\
\hline Equação & $\hat{Y}=0,87+0,002 x-5 e^{-06 x^{2}}$ & $\hat{\mathrm{Y}}=0,80+0,003 \mathrm{x}-8 \mathrm{e}^{-06 x}$ & $\hat{Y}=0,63+2 e^{-06 x}$ & $\hat{Y}=0,64+2 e^{-08 x}$ & \\
\hline \multicolumn{6}{|c|}{$\mathrm{K}\left(\mathrm{g} \mathrm{kg}^{-1}\right)$} \\
\hline 0 & $7,8 \mathrm{a}$ & $7,6 \mathrm{a}$ & $6,7 \mathrm{a}$ & $6,8 \mathrm{a}$ & 27,4 \\
\hline 10 & $10,3 \mathrm{a}$ & $10,8 \mathrm{a}$ & $8,1 \mathrm{ab}$ & $5 \mathrm{~b}$ & 23,2 \\
\hline 50 & $11,2 \mathrm{a}$ & $11,1 \mathrm{a}$ & $7,8 \mathrm{ab}$ & $6,4 \mathrm{~b}$ & 19,4 \\
\hline 100 & $14,1 \mathrm{a}$ & $13,5 \mathrm{a}$ & $11,9 \mathrm{ab}$ & $8,8 \mathrm{~b}$ & 14,3 \\
\hline 150 & $17,2 \mathrm{a}$ & $15,2 \mathrm{a}$ & $9,3 \mathrm{~b}$ & $9,5 \mathrm{~b}$ & 13,7 \\
\hline 200 & $16,1 \mathrm{aA}$ & 17,4 aA & $9,3 \mathrm{bB}$ & $10,5 \mathrm{bB}$ & 20,5 \\
\hline 400 & $22,1 \mathrm{aA}$ & $21,2 \mathrm{aA}$ & $11,1 \mathrm{bB}$ & $11,3 \mathrm{bB}$ & 18 \\
\hline NPK & $18,1 \mathrm{aA}$ & $18,4 \mathrm{aA}$ & $14,6 \mathrm{bA}$ & $14,2 \mathrm{bA}$ & 22,4 \\
\hline Equação & $\hat{\mathrm{Y}}=9,84+0,033 \mathrm{x}$ & $\hat{\mathrm{Y}}=9,75+0,031 \mathrm{x}$ & $\hat{Y}=6,88+0,012 x$ & $\hat{\mathrm{Y}}=7,61+0,010 \mathrm{x}$ & \\
\hline
\end{tabular}

Médias seguidas de letras minúsculas iguais nas linhas não diferem entre si ao nível de 5\% de significância do teste Tukey. Médias seguidas de letras maiúsculas iguais nas colunas não diferem entre si ao nível de 5\% de significância do teste Dunnet.

Fonte: Elaboração dos autores.

No $4^{\circ}$ ciclo não houve variação significativa da PB das plantas em função das doses (Tabela 5). Esta resposta ocorreu devido à suspensão da aplicação do RLL no $2^{\circ}$ ciclo. Sendo o $\mathrm{N}$ elemento diversamente dinâmico, não se manteve no sistema até o $4^{\circ}$ ciclo. Ainda considera-se o fato que neste ciclo foi coletada maior quantidade de massa seca de matéria morta (MSMM) nas maiores doses $(\mathrm{Y}=0,119 \mathrm{x}+$
22,03) o que contribuiu com efeito de diluição da PB. A diminuição da umidade do solo é outro fator que reduz a disponibilidade de N (CANTARELLA, 2007).

No $1^{\circ}$ e $2^{\circ}$ ciclos, embora tenha sido verificado respostar linear da $\mathrm{PB}$ ao RLL, o incremento biológico foi muito discreto. Houve um aumento médio de $0,003 \%$ de $\mathrm{PB}$ na MST para cada $\mathrm{m}^{3}$ 
de RLL aplicado. Esta observação confirma o fato de que o RLL não é bom fornecedor de $\mathrm{N}$ ao sistema solo-planta, sendo o K o principal elemento fornecido. Os baixos valores de PB sob as maiores doses podem estar relacionados ao aumento da participação do componente colmo na massa total, bem como pela perda de $\mathrm{N}$ pelo excesso de água e a imobilização de $\mathrm{N}$ na MO.

A concentração de $\mathrm{P}$ no tecido vegetal se ajustou ao modelo quadrático de regressão no $1^{\circ}$ e $2^{\circ}$ ciclos, havendo aumento até próximo a dose de $200 \mathrm{~m}^{3}$ ha- $^{1}$ (Tabela 5). Esta resposta pode ter ocorrido devido o efeito de diluição do $\mathrm{P}$ em função do aumento da massa seca de colmo (MSC) na massa seca total (MST) (RODRIGUES; REIS, 2010), fato verificado principalmente no $2^{\circ}$ ciclo. Gheri, Ferreira e Da Cruz (2003) também obtiveram resposta quadrática para o teor de $\mathrm{P}$ em função do aumento de doses de soro e Dim et al. (2010) verificaram tendência de efeito quadrático no teor de $\mathrm{P}$ na parte aérea do capim Mombaça em função da aplicação de resíduos sólido de frigorífico.

No $3^{\circ}$ e $4^{\circ}$ ciclos (Tabela 5) a ausência de resposta as aplicações anteriores pode ter ocorrido devido à menor disponibilidade do $\mathrm{P}$ fornecido pelo resíduo e diminuição do estoque na planta devido a elevada remoção de tecidos no $2^{\circ}$ ciclo. A indisponibilização do $\mathrm{P}$ pode acontecer devido suas interações com $\mathrm{Al}^{3+}$. Assim, a fração não absorvida pelas plantas pode ter sido imobilizada no solo após dois ciclos depois da aplicação do calcário. Ainda é relevante o fato do não fornecimento de $\mathrm{N}$ nestes ciclos, que pode ter diminuído a absorção de P (SILVA NETO et al., 2010).

A menor mobilidade de $\mathrm{P}$, aliada a deficiência de água no solo no $4^{\circ}$ ciclo (Tabela 1 ) é outro fator que concorre para eliminar qualquer efeito residual do RLL no $4^{\circ}$ ciclo. Ressalta-se ainda que no $4^{\circ}$ ciclo houve aumento linear da MSMM (Y $=$ $0,119 x+22,03)$ em função das doses, o que poder ter comprometido a concentração de $\mathrm{P}$ na MST (RODRIGUES et al., 2009).
Como a adubação química fosfatada foi realizada em $75 \%$ de sua recomendação em todos os níveis na implantação da pastagem, infere-se que o RLL tenha sido pouco efetivo no aumento da concentração de $\mathrm{P}$ vegetal, possivelmente devido à menor absorção deste elemento, pelos efeitos de diluição e pequeno incremento no solo na forma assimilável (Tabela 5).

Os teores de $\mathrm{K}$ nos tecidos vegetais aumentaram de forma linear com o aumento das doses em todos os ciclos (Tabela 5). O K é o macronutriente mais fornecido pelo resíduo e a partir da dose de $150 \mathrm{~m}^{3}$ extrapolou a recomendação de aplicação (Tabelas 3 e 4), de modo a elevar o estoque do elemento no solo (Tabela 6). Por possuir moderada mobilidade, baixa indisponibilização por interações com outros elementos devido o caráter de ligação eletrostática (ERNANI; ALMEIDA; SANTOS, 2008) e quase nenhuma fixação devido a inexistência de argilas $2: 1$, foi largamente absorvido pelas plantas, tanto quanto maior sua concentração no solo.

Os teores de $\mathrm{K}$ da parte área do capim Mombaça verificados na maior dose, nos ciclo de aplicação do resíduo estiveram acima dos resultados de aplicação de resíduo de frigorífico no capim Marandú (7 a $10 \mathrm{~g} \mathrm{~kg}^{-1}$ ) (SILVA NETO et al., 2010) e capim Mombaça (6,5 $\mathrm{g} \mathrm{kg-}^{-1}$ ) (DIM et al., 2010). Tais respostas demonstram a eficiência de fornecimento de $\mathrm{K}$ do RLL, que a partir da dose de $100 \mathrm{~m}^{3}$ os teores de $\mathrm{K}$ se encontraram na faixa adequada, de 12 a $30 \mathrm{~g} \mathrm{~kg}^{-1}$ segundo Werner, Paulino e Cantarella (1996). Gheri, Ferreira e Da Cruz (2003) também observou aumento na concentração de $\mathrm{K}$ no tecido vegetal com aumento de doses de soro de leite e verificou melhor desempenho na dose de $390 \mathrm{~m}^{3}$ ha $^{-1}$ que correspondia a $736 \mathrm{~kg} \mathrm{~K}_{2} \mathrm{O}$ ha $^{-1}$. Entretanto os resultados destes autores ficaram abaixo dos observados no presente estudo, fato relacionado a diferenças nas dosagens e características químicas do solo. 
Tabela 6. Teores de, $\mathrm{P}, \mathrm{Ca}^{2+}, \mathrm{Mg}^{2+}, \mathrm{Na}^{+}, \mathrm{K}^{+}, \mathrm{Al}^{3+}, \mathrm{H}^{+}+\mathrm{Al}^{3+}$ e Log de $\mathrm{pH}$ e Valores de soma de bases (SB), matéria orgânica (MO), capacidade de troca catiônica efetiva (CTC efetiva), capacidade de troca catiônica a pH 7 (CTC $\mathrm{pH} 7)$, saturação por $\mathrm{Al}^{3+}(\mathrm{m} \%)$, saturação por bases (V\%) no perfil do solo em função de doses de resíduo líquido de Laticínio. * = não significativo. Tratamento NPK não participou da análise de regressão entre as doses.

\begin{tabular}{|c|c|c|c|c|c|c|c|}
\hline & Prof. & Equação & $\mathrm{R}^{2}$ & Item & Prof. & Equação & $\mathrm{R}^{2}$ \\
\hline \multirow{2}{*}{ K } & $0-20$ & $\hat{Y}=0,54-0,002 x+6 e-06 x^{2}$ & 0,63 & \multirow{2}{*}{$\mathrm{Ca}$} & $0-20$ & $\hat{Y}=1,78+0,0015 x$ & 0,53 \\
\hline & $20-40$ & $\hat{Y}=0,58-0,0003 x$ & 0,71 & & $20-40$ & $\hat{Y}=0,56+0,00084 x$ & 0,50 \\
\hline \multirow{2}{*}{$\mathrm{Mg}$} & $0-20$ & $\hat{Y}=1,24+0,0016 x$ & 0,70 & \multirow{2}{*}{$\mathrm{P}$} & $0-20$ & $\hat{Y}=0,64+0,00025 x$ & 0,46 \\
\hline & $20-40$ & $\hat{Y}=0,75^{*}$ & & & $20-40$ & $\hat{Y}=0,51^{*}$ & \\
\hline \multirow{2}{*}{$\mathrm{Na}$} & $0-20$ & $\hat{Y}=3,95+0,007 x$ & 0,89 & \multirow{2}{*}{$\log \mathrm{pH}$} & $0-20$ & $\hat{\mathrm{Y}}=0,71^{*}$ & \\
\hline & $20-40$ & $\hat{Y}=2,5+0,015 x$ & 0,85 & & $20-40$ & $\hat{\mathrm{Y}}=0,64^{*}$ & \\
\hline \multirow{2}{*}{$\mathrm{Al}$} & $0-20$ & $\hat{Y}=0,083+0,0022 x-55 e-06 x^{2}$ & 0,59 & \multirow{2}{*}{$\mathrm{H}+\mathrm{Al}$} & $0-20$ & $\hat{Y}=3,69^{*}$ & \\
\hline & $20-40$ & $\hat{\mathrm{Y}}=3,95-0,00012$ & & & $20-40$ & $\hat{Y}=4,65^{*}$ & \\
\hline \multirow{2}{*}{ SB } & $0-20$ & $\hat{Y}=3,22-0,004 x+9 e-06 x^{2}$ & 0,60 & \multirow{2}{*}{ MO } & $0-20$ & $\hat{Y}=15,2+0,00082 x$ & 0,58 \\
\hline & $20-40$ & $\hat{Y}=1,33+0,0011 x$ & 0,58 & & $20-40$ & $\hat{Y}=15,9+0,0032 x$ & 0,78 \\
\hline \multirow{2}{*}{$\mathrm{V}$} & $0-20$ & $\hat{Y}=45,7-0,002 x+5 e-04 x^{2}$ & 0,60 & \multirow{2}{*}{$\mathrm{m}(\%)$} & $0-20$ & $\hat{Y}=2,59+0,066 x-15 e-04 x^{2}$ & 0,56 \\
\hline & $20-40$ & $\hat{Y}=22,02+0,016 x$ & 0,54 & & $20-40$ & $\hat{Y}=72,1^{*}$ & \\
\hline \multirow{2}{*}{ CTC } & $0-20$ & $\hat{\mathrm{Y}}=3,2^{*}$ & & \multirow{2}{*}{$\begin{array}{c}\text { CTC } \\
(\mathrm{pH} 7)\end{array}$} & $0-20$ & $\hat{\mathrm{Y}}=6,81-0,005+17 \mathrm{e}-05 \mathrm{x}^{2}$ & 0,60 \\
\hline & $20-40$ & $\hat{\mathrm{Y}}=4,89+0,0041 \mathrm{x}$ & 0,52 & & $20-40$ & $\hat{Y}=6,12^{*}$ & \\
\hline
\end{tabular}

Fonte: Elaboração dos autores.

As respostas de PB, P e K em função das doses do resíduo ao longo do tempo encontram-se na Tabela 5. O teor de PB das plantas ao longo dos ciclos foi maior no $1^{\circ}$ e $2^{\circ}$ e diminuiu no $3^{\circ}$ e $4^{\circ}$ ciclos. Esta resposta é atribuída à aplicação do RLL nos dois primeiros ciclos, que forneceu $\mathrm{NH}_{4}^{+}$ e $\mathrm{NO}_{3}{ }^{-}$as plantas (Tabela 4), na época das chuvas, contrastando com o inicio do período seco no $3^{\circ}$ ciclo, além da senescência e acúmulo de biomassa morta no $4^{\circ}$ ciclo (EUCLIDES et al., 2008).

No $3^{\circ}$ ciclo, as doses de 10,50 e $100 \mathrm{~m}^{3}$ a $\mathrm{PB}$ das plantas foi menor que no $4^{\circ}$ ciclo. Já as maiores doses mantiveram concentrações de $\mathrm{N}$ semelhantes nestes ciclos, demonstrando menor variação em função do meio, possivelmente devido a MO e CTC (Tabela 5).

Os teores de $\mathrm{P}$ nas plantas (Tabela 5) dos tratamentos que receberam RLL foram iguais no $1^{\circ}$ e $2^{\circ}$ ciclos. No $3^{\circ}$ e $4^{\circ}$ ciclos os valores de $\mathrm{P}$ novamente não deferiram entre si, porém foram inferiores aos dos ciclos anteriores, possivelmente devido a não existência de efeito residual das aplicações do RLL, dada a menor disponibilização do elemento devido a formação de compostos insolúveis como óxidos e hidróxidos e a baixa quantidade de água no solo limitando a ação de fosfatases (ácidos orgânicos, fenólicos) na região da rizosfera, diminuindo a liberação do $\mathrm{P}$ de compostos insolúveis $\left(\mathrm{POAl}\left(\mathrm{OH}^{-}\right)_{3}\right)$ (SILVA; MENDONÇA, 2007).

As concentrações de P na parte aérea do capim, nos ciclos de aplicação do RLL, foram superiores aos valores encontrados em trabalho com resíduo líquido de frigorífico e de soro, onde se obtiveram de 0,37 a 0,68 e 0,12 a $0,17 \mathrm{~g} \mathrm{~kg}^{-1}$ respectivamente (SILVA NETO et al., 2010; GHERI; FERREIRA; DA CRUZ, 2003), no entanto, neste estudo, ficaram abaixo dos valores preconizados por Werner, Paulino e Cantarella (1996) de 0,8 a $3 \mathrm{~g} \mathrm{~kg}^{-1}$ no $3^{\circ} \mathrm{e}$ $4^{\circ}$ ciclos. Somente sob a dose de $400 \mathrm{~m}^{3}$ os valores do $\mathrm{P}$ do tecido vegetal do $3^{\circ}$ ciclo se igualaram ao $1^{\circ}$ e $2^{\circ}$ ciclos. Tal resposta pode ter ocorrido devido o maior fornecimento de P pela dose de $400 \mathrm{~m}^{3}$, que assegurou um mínimo de resíduo de $\mathrm{P}$ disponível no solo, bem como ao efeito de reservas da planta. 
A concentração de K nas plantas (Tabela 5) sob as doses ao longo dos ciclos foi semelhante durante o $1^{\circ}$ e $2^{\circ}$ ciclos e diminuíram no $4^{\circ}$ ciclo. No $3^{\circ}$ ciclo, como as doses de 10,50 e $100 \mathrm{~m}^{3}$ promoveram incremento no teor de $\mathrm{K}^{+}$vegetal no $1^{\circ}$ e $2^{\circ}$ ciclos, a concentração do elemento neste ciclo não diferiu dos primeiros. Para as demais doses do resíduo, que promoveram maior incremento na concentração de $\mathrm{K}^{+}$vegetal nos ciclos tratados com o RLL, os teores de $\mathrm{K}^{+}$das plantas foram menores no $3^{\circ}$ ciclo em relação os ciclos anteriores. No $4^{\circ}$ a deficiência hídrica diminuiu os processos de absorção devido aos fatores quantidade/intensidade de $\mathrm{K}^{+}$no solo (ERNANI; ALMEIDA; SANTOS, 2008).

As concentrações de $\mathrm{K}^{+}\left(\mathrm{g} \mathrm{kg}^{-1}\right)$ da parte aérea ficaram dentro da faixa aceitável (12 a $30 \mathrm{~g} \mathrm{~kg}^{-1}$ de $\mathrm{K}^{+}$) a partir da dose de $100 \mathrm{~m}^{3} \mathrm{ha}^{-1}$ no $1^{\circ}$ e $2^{\circ}$ ciclos para gramíneas como Colonião, Andropogon, Napier e Marandú (BOREATTO et al., 2009).

O tratamento adicional NPK, quando comparado aos tratamentos 200 e $400 \mathrm{~m}^{3}$ de RLL (Tabela 5), promoveu maiores concentrações de $\mathrm{PB}$ e $\mathrm{P}$ no tecido vegetal no $3^{\circ}$ e $4^{\circ}$ ciclos e ao longo dos ciclos os valores diminuíram do $1^{\circ}$ e $2^{\circ}$ para o $3^{\circ}$ e $4^{\circ}$ ciclos. Somente o $\mathrm{K}^{+}$do tecido vegetal do tratamento NPK foi inferior a dose de $400 \mathrm{~m}^{3}$ no $1^{\circ}$ e $2^{\circ}$ ciclos. A PB e o $\mathrm{P}$ apresentaram menor concentração no $1^{\circ}$ ciclo em relação ao $2^{\circ}$ provavelmente devido a ocorrência de chuvas imediatamente após a adubação. O tratamento NPK apresentou efeito residual para PB, $\mathrm{P}$ e $\mathrm{K}^{+}$em relação as doses de 200 e $400 \mathrm{~m}^{3}$, como observado por Oliveira et al. (2008).
As extrações dos nutrientes $\mathrm{N}, \mathrm{P}$ e $\mathrm{K}^{+}$(Tabela 7) aumentaram de forma linear com a aplicação do RLL nos quatro ciclos estudados, em virtude do aumento da produção de biomassa em função das doses. Isto pode ter promovido a diminuição de $\mathrm{Mg}^{2+}$, aumento do $\mathrm{Al}^{3+}$ e diminuição da SB no solo até a dose de $200 \mathrm{~m}^{3} \mathrm{ha}^{-1}$. As plantas do $2^{\circ}$ ciclo apresentaram elevada extração, já que houve maior crescimento do capim possivelmente devido estabelecimento da cultura $(Y=211,25+2,15 x)$. Já no $4^{\circ}$ ciclo obteve-se a menor extração já que houve o menor crescimento $(\mathrm{Y}=93,8+0,53 \mathrm{x})$ do capim em função da seca. Sob as maiores doses, a extração do $4^{\circ}$ ciclo igualou-se a do $2^{\circ}$ demonstrando maior crescimento do capim devido o efeito residual do RLL e do aumento da matéria orgânica do solo (Tabela 7) que pode reter vinte vezes seu peso em água (SILVA; MENDOÇA, 2007). As extrações de $\mathrm{N}$ foram superiores ao fornecimento via resíduo, demonstrando haver efeito positivo do aumento da matéria orgânica do solo (Tabela 7) e umidade.

Para as doses 0, 10, 50, 100, 150, 200 e 400 $\mathrm{m}^{3} \mathrm{ha}^{-1}$ de RLL foram extraídos ao final de quatro ciclos produtivos respectivamente: 49,7; 92,7; 120,$7 ; 154,4 ; 162,9 ; 175,4$ e $227 \mathrm{~kg} \mathrm{ha}^{-1}$ de $\mathrm{N} ; 2,6$; 5,$6 ; 7,8 ; 9,5 ; 10 ; 9,6$ e $11,3 \mathrm{~kg} \mathrm{ha}^{-1}$ de $\mathrm{P}$ e 26,6 ; 61,$7 ; 87,6 ; 143,8 ; 152,1 ; 161,3$ e $246,8 \mathrm{~kg} \mathrm{ha}^{-1} \mathrm{de}$ $\mathrm{K}^{+}$. O Tratamento NPK extraiu 207,9 $\mathrm{kg} \mathrm{ha}^{-1}$ de N; $11,3 \mathrm{~kg} \mathrm{ha}^{-1}$ de $\mathrm{P}$ e $208 \mathrm{~kg} \mathrm{ha}^{-1}$ de $\mathrm{K}^{+}$, igualando a dose de $400 \mathrm{~m}^{3} \mathrm{ha}^{-1}$. Paris (2010) obteve extração máxima de $\mathrm{N}$ pelo capim Mombaça de $140,8 \mathrm{~kg}$ ha $^{-1}$ ciclo $^{-1}$, ao aplicar $200 \mathrm{~kg} \mathrm{ha}^{-1}$ de $\mathrm{N}$ e observou menor aproveitamento. Já Silva Neto et al. (2010) observaram extração de $\mathrm{N}$ de apenas $62,2 \mathrm{~kg} \mathrm{ha}^{-1} \mathrm{e}$ 2,37 kg ha-1 de $\mathrm{P}_{\text {ciclo }}^{-1}$, ao aplicar $112,5 \mathrm{~m}^{3} \mathrm{ha}^{-1} \mathrm{de}$ RLF. 
Tabela 7. Extração dos nutrientes N, P e K pelo capim Mombaça em função de doses de resíduo líquido de laticínio em quatro ciclos produtivos.

\begin{tabular}{|c|c|c|c|c|c|c|c|c|c|c|c|c|}
\hline & \multicolumn{4}{|c|}{$\mathrm{N}\left(\mathrm{g} \mathrm{m}^{-2}\right)$} & \multicolumn{4}{|c|}{$\mathrm{P}\left(\mathrm{g} \mathrm{m}^{-2}\right)$} & \multicolumn{4}{|c|}{$\mathrm{K}\left(\mathrm{g} \mathrm{m}^{-2}\right)$} \\
\hline Tratamento & $1^{\circ}$ & $2^{\circ}$ & $3^{\circ}$ & $4^{\circ}$ & $1^{\circ}$ & $2^{\circ}$ & $3^{\circ}$ & $4^{\circ}$ & $1^{\circ}$ & $2^{\circ}$ & $3^{\circ}$ & $4^{\circ}$ \\
\hline 0 & $1,04 b c$ & $2,01 \mathrm{a}$ & $1,33 b$ & $0,59 \mathrm{c}$ & $0,06 \mathrm{~b}$ & $0,09 a$ & $0,07 a b$ & $0,04 \mathrm{~b}$ & $0,54 \mathrm{~b}$ & $1,07 \mathrm{a}$ & $0,66 a b$ & $0,39 b$ \\
\hline 10 & $2,98 b$ & $3,9 \mathrm{a}$ & $1,44 \mathrm{c}$ & $0,95 \mathrm{~d}$ & $0,17 \mathrm{~b}$ & $0,21 \mathrm{a}$ & $0,12 \mathrm{c}$ & $0,06 \mathrm{~d}$ & $1,94 \mathrm{~b}$ & $2,70 \mathrm{a}$ & $0,82 \mathrm{c}$ & $0,71 \mathrm{c}$ \\
\hline 50 & $3,44 \mathrm{~b}$ & $5,34 \mathrm{a}$ & $1,73 \mathrm{c}$ & $1,56 \mathrm{c}$ & $0,21 b$ & $0,35 \mathrm{a}$ & $0,14 \mathrm{c}$ & $0,08 \mathrm{~d}$ & $2,43 b$ & $3,95 \mathrm{a}$ & $1,40 \mathrm{bc}$ & $0,98 \mathrm{c}$ \\
\hline 100 & $3,68 \mathrm{~b}$ & $7,20 \mathrm{a}$ & $2,59 \mathrm{~b}$ & $2,47 b$ & $0,25 \mathrm{~b}$ & $0,45 \mathrm{a}$ & $0,14 \mathrm{c}$ & $0,11 \mathrm{c}$ & $3,25 \mathrm{~b}$ & $6,02 \mathrm{a}$ & $3,30 \mathrm{~b}$ & $1,81 \mathrm{~b}$ \\
\hline 150 & $3,53 \mathrm{~b}$ & $8,30 \mathrm{a}$ & $2,72 b c$ & $1,74 \mathrm{c}$ & $0,22 \mathrm{~b}$ & $0,51 \mathrm{a}$ & $0,17 b c$ & $0,10 \mathrm{c}$ & $3,77 \mathrm{~b}$ & $7,46 a$ & $2,55 \mathrm{c}$ & $1,43 \mathrm{c}$ \\
\hline 200 & $3,84 \mathrm{bcB}$ & $6,74 \mathrm{aB}$ & $4,06 \mathrm{bB}$ & $2,90 \mathrm{cB}$ & $0,24 \mathrm{bA}$ & $0,38 \mathrm{aA}$ & $0,20 \mathrm{bB}$ & $0,14 \mathrm{cB}$ & $3,81 \mathrm{bB}$ & $7,00 \mathrm{aA}$ & $2,91 \mathrm{bB}$ & $2,41 \mathrm{bB}$ \\
\hline 400 & $4,20 \mathrm{cA}$ & $9,16 \mathrm{aA}$ & $5,82 \mathrm{bB}$ & $3,52 \mathrm{cB}$ & $0,23 \mathrm{bcA}$ & $0,36 \mathrm{aA}$ & $0,32 \mathrm{abA}$ & $0,17 \mathrm{cA}$ & $5,53 \mathrm{bA}$ & $10,9 \mathrm{aA}$ & $6,93 \mathrm{bA}$ & $3,32 \mathrm{bA}$ \\
\hline NPK & $3,26 \mathrm{cB}$ & $5,71 \mathrm{bB}$ & 7,7aA & $4,12 \mathrm{cA}$ & $0,20 \mathrm{cB}$ & $0,32 \mathrm{bB}$ & $0,43 \mathrm{aA}$ & $0,18 \mathrm{cA}$ & $3,54 \mathrm{bB}$ & $4,15 \mathrm{bB}$ & $9,41 \mathrm{aA}$ & $3,74 \mathrm{bA}$ \\
\hline$\beta_{0}$ & 2,58 & 4,16 & 1,32 & 1,07 & 0,16 & 0,27 & 0,095 & 0,06 & 1,66 & 2,65 & 1,04 & 0,76 \\
\hline$\beta_{1}$ & 0,005 & 0,014 & 0,011 & 0,007 & 2-E04 & 5-E04 & 5-E04 & 3-E04 & 0,010 & 0,020 & 0,010 & 0,007 \\
\hline $\mathrm{R}^{2}$ & 0,64 & 0,68 & 0,98 & 0,81 & 0,49 & 0,46 & 0,95 & 0,88 & 0,86 & 0,90 & 0,86 & 0,92 \\
\hline $\mathrm{CV}$ & 17,6 & 11,0 & 8,5 & 16,4 & 17,5 & 18,6 & 12,2 & 13,8 & 24,8 & 31,9 & 22,7 & 34,3 \\
\hline
\end{tabular}

Médias seguidas de letras minúsculas iguais nas linhas não diferem entre si ao nível de $5 \%$ de probabilidade do teste Tukey. Médias seguidas de letras maiúsculas iguais nas colunas não diferem entre si ao nível de 5\% de probabilidade do teste Dunnet.

Fonte: Elaboração dos autores.

O tratamento adicional NPK, quando comparado as doses de 200 e $400 \mathrm{~m}^{3}$ de RLL (Tabela 6) apresentou menor extração de nutrientes no $1^{\circ}$ e $2^{\circ}$ ciclos, possivelmente devido o menor crescimento nestes ciclos, já que as concentrações de nutrientes não variaram entre estes tratamentos (Tabela 5). No $3^{\circ}$ e $4^{\circ}$ ciclos o tratamento NPK apresentou extração de $\mathrm{N}$ maior, e de $\mathrm{P}$ e $\mathrm{K}$ semelhante a extração da dose de $400 \mathrm{~m}^{3}$.

A aplicação de doses crescentes de resíduo líquido de laticínio (RLL) afetou as características químicas do solo cultivado com o capim Mombaça (Tabela 7) principalmente na profundidade de $0-$ $20 \mathrm{~cm}$. O teor de C orgânico do solo aumentou em função dos níveis de RLL nas duas profundidades, com dados ajustados ao modelo linear da regressão. Devido a baixa carga orgânica do RLL e compostos de alta degradabilidade, como observado por Ricci, Padovani e Paula Junior (2010) e Silva Neto et al. (2010), infere-se que a deposição de raízes do capim concorreu para aumentar a MO conforme maior dose e maior crescimento da planta (SILVA; MENDONÇA, 2007).

A diminuição da concentração de $\mathrm{N}$ e $\mathrm{P}$ no tecido vegetal, no $3^{\circ}$ e $4^{\circ}$ ciclos, pode estar relacionado à diminuição da disponibilização destes elementos (CANTERELLA, 2007). Provavelmente a menor precipitação neste período afetou negativamente a absorção destes pelas raízes (visto que o fluxo de massa e a difusão são os principais mecanismos de contato íon-raiz para $\mathrm{N}$ e $\mathrm{P}$, respectivamente), e por sua vez o menor desenvolvimento das plantas além da senescência dos tecidos vegetais podem explicar este fenômeno observado. Silva e Mendonça (2007) relatam imobilização de elementos como $\mathrm{N}$ e $\mathrm{P}$ devido o aumento da MO, após o fornecimento de resíduos orgânicos, mas com a continuação da prática os processos de imobilização/mineralização tendem a se equilibrar.

Os teores de $\mathrm{P}, \mathrm{Ca}^{2+}, \mathrm{Na}^{+}$e principalmente o $\mathrm{K}^{+}$aumentaram no solo com aumento da doses do RLL se ajustando ao modelo linear de regressão na camada de 0-20 $\mathrm{cm}$. Também houve acréscimo do $\mathrm{K}^{+}, \mathrm{Ca}^{2+}$ e $\mathrm{Na}^{+}$na camada de 20-40 cm (Tabela 7).

O P trocável, devido sua menor mobilidade e fornecimento via resíduo, não variou na camada mais profunda e pode ter ocorrido de acordo com Monteiro et al. (1995) devido a extração ter aumentado de forma linear ou a processos de 
imobilização devido a baixa relação C:P (300:1). Na camada de 0-20 o P aumentou significativamente com o acréscimo das doses, fato também observado por Ricci Padovani e Paula Junior (2010) ao aplicar lodo de esgoto no solo. Entretanto, o incremento de $\mathrm{P}$ para cada $1 \mathrm{~m}^{3}$ do RLL foi muito baixo, de modo que a concentração de $\mathrm{P}$ ficou classificada como muito baixo (COLLIER et al., 2008) mesmo após fornecimento do RLL.

A adição do RLL promoveu aumento linear no teor de $\mathrm{K}^{+}$na camada de 0-20 devido à elevada concentração de $\mathrm{K}^{+}$no RLL, oriundo do leite e de sanitizantes. Na camada de 20-40 o $\mathrm{K}^{+}$se ajustou a resposta quadrática com ponto de máxima próximo a dose de $200 \mathrm{~m}^{3}$, já que a menor dose as plantas exploraram pouco esta zona e sob a maior dose houve aumento no estoque. Apesar do aumento do $\mathrm{K}^{+}$no solo, seu teores ficaram abaixo do preconizado para CTC pH 7 que deve encontrar-se em torno de $45 \mathrm{mg}$ $\mathrm{dm}^{-3}$ (ERNANI; ALMEIDA; SANTOS, 2008).

Os teores de $\mathrm{Ca}^{2+}$ e $\mathrm{Mg}^{2+}$ também foram influenciados pela adição do RLL (Tabela 7). Os teores de $\mathrm{Ca}^{2+}$ aumentaram linearmente nas duas camadas sendo que a maior concentração na camada de 0-20 cm esta relacionada a calagem, a baixa lixiviação desta base (RICCI; PADOVANI; PAULA JUNIOR, 2010) e a possível diminuição da absorção deste cátion em função do aumento do $\mathrm{Na}^{+}$(FARIAS et al., 2009). O teor de $\mathrm{Mg}^{2+}$ diminuiu linearmente em função do aumento das doses devido à maior extração com o aumento dos níveis (WERNER; PAULINO; CANTARELLA, 1996). A não significância dos níveis na camada de 20-40 demonstra a menor capacidade de fornecimento deste elemento pelo resíduo (GHERI; FERREIRA, DA CRUZ, 2003).

A acidez potencial não foi afetada pelo aumento das doses do RLL nas duas profundidades, resposta também observada por Ricci, Padovani e Paula Junior (2010) ao aplicarem lodo de esgoto estabilizado obtido por sistemas de lodos ativados por batelada misturado com resíduo de roçagem em leiras revolvidas no solo. Na camada de 0-20 cm o aumento do $\mathrm{Al}^{3+}$ até a dose de $200 \mathrm{~m}^{3}$ devido à extração de bases foi acompanhado pela diminuição do $\mathrm{H}^{+}$no colóide em função da diferença de cargas, entretanto o $\mathrm{H}^{+}$representou $85,7 \%$ da acidez potencial. Já na profundidade de $20-40 \mathrm{~cm}$ devido à menor atividade de troca iônica coloidal, o $\mathrm{Al}^{3+}$ foi cerca de $80 \%$ da acidez potencial.

$\mathrm{O}$ aumento do $\mathrm{Al}^{3+}$ de $20-40 \mathrm{~cm}$ de forma linear, ocorreu devido a extração dos cátions bases pela cultura, como observado por Roscoe et al. (2006), revelando crescimento das raízes e pouca efetividade da calagem nesta profundidade. Na camada de 0-20 $\mathrm{cm}$ o $\mathrm{Al}^{3+}$ apresentou comportamento quadrático em função das doses, com o ponto de máxima na dose de $200 \mathrm{~m}^{3}$ (Tabela 7). Este fato é explicado devido extração de bases, até esta dose, ser maior que o fornecimento de bases via resíduo; já a dose de 400 $\mathrm{m}^{3}$ atendeu as exigências das plantas e elevou o estoque de bases no solo, resposta idêntica a aquela encontrada por Silva Neto et al. (2010).

A CTC efetiva na profundidade de $20-40 \mathrm{~cm}$ aumentou linearmente em função das doses do RLL (Tabela 7), o que seria esperado devido o aumento linear da SB e MO na profundidade de 20$40 \mathrm{~cm}$, porém, nesta situação, teve como principal componente o $\mathrm{Al}^{3+}$. Este fato concorreu para que a SB fosse somente $50 \%$ em média da SB de 0-20, promovendo o mesmo efeito no V\%. A CTC de 0-20 não variou em função das doses, condição também observada por DIM et al. (2010) ao aplicar resíduo sólido de frigorífico em pastagem de capim Marandu, já que o fornecimento de bases pelo resíduo e sua extração foi balanceado com o $\mathrm{H}^{+}$.

A SB na profundidade de $0-20 \mathrm{~cm}$ se ajustou ao modelo quadrático de regressão com o ponto de mínima na dose de $200 \mathrm{~m}^{3} \mathrm{ha}^{-1}$ (Tabela 7). Este fato ocorreu porque a dose de $400 \mathrm{~m}^{2} \mathrm{ha}^{-1}$ manteve o crescimento da cultura e assegurou o estoque de bases no solo, enquanto que nas menores doses a extração dos elementos não foi compensada pela adição, refletindo na redução dos estoques do solo devido o crescimento do capim (SILVA NETO et al., 2010). 
Dos principais elementos fornecidos pelo RLL o principal componente da SB na profundidade de 0-20 foi o $\mathrm{K}^{+}$seguido do $\mathrm{Na}^{+}$, enquanto que para a SB de 20-40 de profundidade o $\mathrm{Na}^{+}$foi o principal cátion que compôs a $\mathrm{SB}$, principalmente nas maiores doses. Esta resposta revela, nas maiores doses, a lixiviação de $\mathrm{Na}^{+}$, para a camada de $20-40 \mathrm{~cm}$, já que este elemento não é absorvido pelo capim sob situações de concentração razoável de $\mathrm{K}^{+}$(ERNANI; ALMEIDA; SANTOS, 2008). Assim, a aplicação de RLL contribuiu para elevar a concentração de $\mathrm{Na}$ nas camadas avaliadas. Segundo Farias et al. (2009) a salinidade do solo limita o crescimento das plantas pela redução do potencial osmótico. Como a diminuição de $\mathrm{K}^{+}$é uma das principais injurias que atingem plantas sob solos salinos, infere-se que o aumento do teor de $\mathrm{Na}^{+}$neste estudo não tenha afetado significativamente o desempenho do capim devido o aumento do $\mathrm{K}^{+}$.

$\mathrm{O}$ valor $\mathrm{V} \%$ na profundidade de $0-20 \mathrm{~cm}$ foi afetado pelo RLL em função da SB. Houve ajuste ao modelo quadrático de regressão, ponto de mínima a dose de $180 \mathrm{~m}^{3}$, já que o aumento das doses elevou a extração, diminuindo as bases até próximo a dose de $200 \mathrm{~m}^{3}$ (ROSCOE et al., 2006) (Tabela 7). Já a dose de $400 \mathrm{~m}^{3}$ elevou o estoque de bases do solo. DIM et al. (2010) também verificaram comportamento quadrático da V\% em função da aplicação de resíduos e atribuiu a diminuição deste atributo após o ponto de máxima, devido a estabilização em função da limitação da CTC. A V\% na profundidade de 20-40 ajustou-se ao modelo linear já que a SB de 20-40 cm aumentou pelo incremento de $\mathrm{Ca}^{2+}$ e, principalmente, $\mathrm{Na}^{+}$e $\mathrm{K}^{+}$nas maiores doses do RLL e a CTC pH7 de 20-40 cm não variou.

$\mathrm{O}$ pH do solo não sofreu variações significativas com a aplicação das doses do resíduo (Tabela 7) nas duas camadas avaliadas. Fatores como a diminuição do $\mathrm{Mg}^{2+}$ ou a substituição de parte das bases extraídas por $\mathrm{Al}$, tendo em vista o equilíbrio entre $\mathrm{H}$ e $\mathrm{Al}$, podem ter colaborado para tal resultado. $\mathrm{Na}$ camada de 0-20 cm observou-se diminuição do $\mathrm{pH}$ até a dose de $200 \mathrm{~m}^{3}$. Isto pode ter ocorrido devido o aumento na extração das bases pelo aumento do crescimento das plantas. Já a dose de $400 \mathrm{~m}^{3}$, apesar da maior extração, manteve elevada a concentração de bases no solo. A ausência de efeito do resíduo sobre o $\mathrm{pH}$ ainda pode estar relacionada ao fato do baixo fornecimento de $\mathrm{N}$ nas formas amoniacais, pois na nitrificação ou oxidação a nitrato são produzidos dois prótons $\left(\mathrm{H}^{+}\right)$para cada dos íon $\mathrm{NH}_{4}^{+}$nitrificado (SILVA NETO et al., 2010).

$\mathrm{O}$ tratamento NPK nas profundidades de 0-20 e 20-40 cm não elevou os teores de $\mathrm{Na}^{+}$em relação à testemunha do RLL e apresentou menor capacidade de aumentar o $\mathrm{K}^{+}$do solo em relação à maior dose (Tabela 7). Manteve a SB igual à maior dose e elevou o P do solo em relação a todas as doses. A $\mathrm{MO}$ igualou-se as maiores doses, possivelmente pelo incremento radicular, e manteve a CTC e V\% semelhante às maiores doses (Tabela 7).

\section{Conclusões}

O aumento das doses do resíduo líquido de laticínio eleva o teor de proteína bruta, fósforo e potássio do capim Mombaça e amplia a extração de nutrientes.

A dose de $400 \mathrm{~m}^{3} \mathrm{ha}^{-1}$ de resíduo liquido de

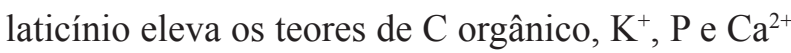
do solo alterando positivamente a fertilidade do Neossolo Quartzarênico.

O resíduo líquido de laticínio apresenta potencial de salinização sódica do solo.

O uso do resíduo líquido de laticínio vislumbra potencial para a substituição parcialmente da adubação fosfatada e completamente a adubação potássica.

\section{Agradecimentos}

Ao CNPq (PQ 10/2009 - Produtividade em Pesquisa - 2009) e CAPES pela concessão das bolsas de estudos. 


\section{Referências}

BOARETTO, A. E.; RAIJ, B. V.; SILVA, F. C.; CHITOLINA, J. C.; TADESCO, M. J.; CAMO, C. A. F. S. In: SILVA, F. C. da. Manual de análises químicas de solo, plantas e fertilizantes. 2. ed. rev. e e ampl. Brasília, DF: Embrapa, 2009. parte 2, cap. 1, p. 120.

CANTARELLA, H. Nitrogênio. In: NOVAIS, F.; ALVAREZ, V. H.; BARROS, N. F.; FONTES, R. L. F.; CANTARUTTI, R. B.; NEVES, J. C. L. Fertilidade do solo. Viçosa, MG: Sociedade Brasileira de Ciência do Solo, 2007, p. 376.

COLLIER, L. S.; LARA, M. A. S.; VILELA, L.; SIQUEIRA, F. L. T. Recomendação de adubação e calagem a partir do manejo da forrageira de solos cultivados com pastagens no cerrado. In: SANTOS, A. C. Do campus para o campo. Araguaína, TO: Gráfica Ed. Impacto, 2008, p. 16.

DIM, V. P.; CASTRO, J. G. D.; ALEXANDRINO, E.; SANTOS, A. C.; SILVA NETO, S. P. Fertilidade do solo e produtividade de capim Mombaça adubado com resíduos sólidos de frigorífico. Revista Brasileira de Saúde e Produção Animal, Salvador, v. 11, n. 2, p. 303316, 2010.

EMPRESA BRASILEIRA DE PESQUISA AGROPECUÁRIA - EMBRAPA. Centro nacional de pesquisa em solo. Sistemas brasileiro de classificação de solos. 2. ed. Brasília: Embrapa, 2006. 306 p.

ERNANI, P. R.; ALMEIDA, J. A.; SANTOS, F. C. Potássio. In: NOVAIS, F.; ALVAREZ, V. H.; BARROS, N. F.; FONTES, R. L. F.; CANTARUTTI, R. B.; NEVES, J. C. L. Fertilidade do solo. Viçosa, MG: Sociedade Brasileira de Ciência do Solo, 2008. p. 553.

EUCLIDES, V. P. B.; MACEDO, M. C. M.; VALLE, C. B. do; BARBOSA, R. A.; GONÇALVES, W. V. Produção de forragem e características da estrutura do dossel de cultivares de Brachiaria brizantha sob pastejo. Pesquisa Agropecuária Brasileira, Brasília, v. 43, p. 1805-1812, 2008.

FARIAS, S. G. G.; SANTOS, D. R.; FREIRE, A. L.; SILVA, R. B. Estresse salino no crescimento inicial e nutrição mineral de Gliricídia (Gliricídia sepium (Jacq) Kunth ex Stued) em solução nutritiva. Revista Brasileira de Ciência do Solo, Viçosa, MG, v. 33, n. 5, p. 14991505, 2009.

GHERI, E. O.; FERREIRA, M. E.; DA CRUZ, M. C. P. Resposta do capim-tanzânia à aplicação de soro ácido de leite. Pesquisa Agropecuária Brasileira, Brasília, v. 38, n. 6, p. 753-760, 2003.
INSTITUTO NACIONAL DE METEOROLOGIA INMET. 2010. Disponível em: <http://www.inmet.gov. br/>. Acesso em: 01 outt. 2010.

McDOWELL, R. W.; KOOPMARS, G. F. Assessing the bioavailability of dissolved organic phosphorus in pasture and cultivated soils treated with different rater of nitrogen fertilizer. Soil Biology and Biochemistry, Oxford, v. 38, n. 38, p. 61-70, 2006.

MEDEIROS, L. T.; REZENDE, A. V.; VIEIRA, P. F.; CUNHA NETO, F. R.; VALERIANO, A. R.; CASALI, A. O.; GASTALDELlO JUNIOR, A. L. Produção e qualidade da forragem de capim-marandu fertiirrigada com dejetos líquidos de suínos. Revista Brasileira de Zootecnia, Viçosa, MG, v. 36, n. 2, p. 309-318, 2007.

MESQUITA, E. E.; CARDOSO PINTO, J.; FURTINI NETO, A. E.; SANTOS, I. P. A.; TAVARES, V. B. Teores críticos de fósforo em três solos para o estabelecimento de capim mombaça, capim marandú e capim andropogon em vasos. Revista Brasileira de Zootecnia,Viçosa, MG, v. 33, n. 2, p. 290-301, 2004.

MONTEIRO, F. A.; RAMOS, A. K. B.; CARVALHO, D. D.; ABREU, J. B. R.; DAIUB, J. A. S.; SILVA, J. E. P.; NATALE, W. Cultivo de Brachiaria brizantha cv. Marandu em solução nutritiva com omissões de macronutrientes. Scientia Agricola, Piracicaba, v. 52, n. 1, p. 135-141, 1995.

OLIVEIRA, D. Q. L.; CARVALHO, K. T. G.; BASTOS, A. R. R.; OLIVEIRA, L. C. A.; MARQUES, J. J. G. S. M.; NASCIMENTO, R. S. M. P. Utilização de resíduos da indústria de couro como fonte nitrogenada para o capim-elefante. Revista Brasileira de Ciência do Solo, Viçosa, MG, v. 32, n. 1, p. 417-424, 2008.

PARIS, C. M. Desempenhos técnicos e econômicos de um sistema de integração lavoura-pecuária com a cultura do milho e adubação nitrogenada de capins dos gêneros panicum e brachiaria sob irrigação no cerrado. 2010. Dissertação (Mestrado em Agornomia) - Universidade Estadual Paulista Júlio de Mesquita Filho, Ilha Solteira.

RICCI, A. B.; PADOVANI, V. C. R.; PAULA JUNIOR, D. R. Uso de lodo de esgoto estabilizado em um solo decapitado. II atributos químicos e revegetação. Revista Brasileira de Ciência do Solo, Viçosa, MG, v. 34, n. 2, p. 543-551, 2010.

RODRIGUES, A. M.; CECATO, U.; DAMASCENO, J. S.; GALBEIRO, J. A. N.; GOMES, L. Produção, quantidade e concentração de macronutrientes do material morto de capim-mombaça, fertilizado com fontes de fósforo. Arquivo Brasileiro de Medicina Veterinária e Zootecnia, Belo Horizonte, v. 61, n. 2, p. 445-451, 2009. 
RODRIGUES, J. F.; REIS, J. M. R. Teores de bases no capim tanzânia em função de doses de fósforo, em um latossolo vermelho distroférrico da região do cerrado, Enciclopédia Biosfera, Goiânia, v. 6, n. 10, p. 1-8, 2010.

ROSCOE, R.; NUNES, W. A. G. A; SAGRILO, E.; ORSUBA, A. A. Aproveitamento agrícola de resíduos de frigorifico como fertilizante orgânico sólido. Dourados: Embrapa Agropecuária Oeste, 2006. p. 7-10. (Boletim de Pesquisa e Desenvolvimento, 35).

SILVA NETO, S. P.; SILVA, J. E. C.; SANTOS, A. C.; DIAZ CASTRO, J. G.; DIM, V. P.; ARAÚJO, A. S. Características agronômicas e nutricionais do capimMarandu em função da aplicação de resíduo líquido de frigorífico. Acta Scien. Anim. Sciences, Maringá, v. 32, n. 1, p. 9-17, 2010.
SILVA, I. R.; MENDONÇA, E. S. Matéria orgânica do solo. In: NOVAIS, F.; ALVAREZ, V. H.; BARROS, N. F.; FONTES, R. L. F.; CANTARUTTI, R. B.; NEVES, J. C. L. Fertilidade do solo. Viçosa, MG: Sociedade Brasileira de Ciência do Solo, 2007. p. 276.

WERNER, J. C.; PAULINO, V. T.; CANTARELLA, H. Forrageiras. In: RAIJ, B. van; CANTARELLA, H.; QUAGGIO, J. A.; FURLANI, A. M. C. (Ed.). Recomendações de adubação e calagem para o Estado de São Paulo. Campinas: Instituto Agronômico, 1996. p. 263-273. (Boletim técnico, 100). 